\title{
Note for Contributors
}

Journal of Language Relationship welcomes submissions from everyone specializing in comparative-historical linguistics and related disciplines, in the form of original articles as well as reviews of recent publications. All such submissions should be sent to the managing editor:

\author{
G. Starostin \\ Institute for Oriental and Classical Studies \\ Russian State University for the Humanities \\ 125267 Moscow, Russia \\ Miusskaya Square, 6 \\ E-mail: gstarst@rinet.ru
}

Articles are published preferably in English or Russian, although publication of texts in other major European languages (French, German, etc.) is possible. Each article should be accompanied with an abstract (not exceeding 300 words) and keywords.

For more detailed guidelines on article submission and editorial policies, please see our website at: http://www.jolr.ru or address the editorial staff directly at gstarst@rinet.ru.

\section{Будущим авторам}

Журнал Вопросы языкового родства принимает заявки на публикацию оригинальных научных статей, а также рецензий от всех, кто специализируется в области сравнительно-исторического языкознания и смежных дисциплин. Рукописи можно высылать непосредственно заместителю главного редактора по адресу:

125267 Москва

Миусская площадь, д. 6

Российский государственный гуманитарный университет

Институт восточных культур и античности

Г. Старостину

E-mail: gstarst@rinet.ru

Предпочтительные языки публикации - английский или русский, хотя возможна также публикация статей на других европейских языках (французский, немецкий и т. п.). К каждой статье обязательно прикладывается резюме (не более 300 слов) и список ключевых слов.

Подробнее о требованиях к оформлению рукописи, редакционной политике журнала и т. п. вы можете узнать на нашем сайте по адресу: http://www.jolr.ru или же непосредственно, обратившись к редакции по электронной почте (gstarst@rinet.ru). 